\title{
Development of a Sensitive PCR to Detect Allele Loss in a Model Hematopoietic Neoplasm
}

\author{
Jeffery Fairman,, David Claxton ${ }^{1}$, Cheryl L. Willman, ${ }^{2}$ Albert B. Deisseroth, ${ }^{1}$ and \\ Lalitha Nagarajan ${ }^{1}$
}

\footnotetext{
${ }^{1}$ Department of Hematology, The University of Texas M.D. Anderson Cancer Center, Houston, Texas 77030; ${ }^{2}$ Cell Biology and Pathology, Center for Molecular and Cellular Diagnostics, The University of New Mexico, Albuquerque, New Mexico 87131
}

\begin{abstract}
Loss or gain of an entire chromosome and interstitial deletions or amplifications are hallmarks of several hematopoietic neoplasms. These chromosomal anomalies can be identified by conventional cytogenetic analysis of bone marrow aspirates. We have developed a PCR-based assay to detect loss of chromosome $5 q 31$ loci, in the model system of myeloid disorders with the 5q-chromosome (interstitial deletion of $5 q$ ), by taking advantage of a highly polymorphic dinucleotide repeat within the interleukin-9 (IL9) gene on 5q31. In a given sample, quantitation of amplification of individual alleles in a Phosphorimager allowed the representation of alleles to be expressed as a ratio of the larger to the smaller allele. Comparison of these ratios in paired DNA samples from Ficoll buoyant and pelletted fractions provides evidence for allele loss. Results presented here demonstrate that this technique of comparison of ratios of isotope incorporation could be expanded to investigate any deletion or numerical abnormality in hematopoietic tumors.
\end{abstract}

$\mathbf{N}$ anomalies are frequently associated with neoplasms. The loss of portions of the long arm of chromosomes 5 and 7, the trisomy 8 seen in myelodysplasia and acute myelogenous leukemia, the loss of $9 p$ sequences in chronic lymphocytic leukemia, and interstitial deletion of $6 \mathrm{q}$ material associated with nonfollicular lymphomas are karyotypic markers for these hematopoietic neoplasms. ${ }^{(1)}$ At present, these anomalies are identified by loss of heterozygosity for specific loci, as detected by Southern analyses or fluorescent in situ hybridization (FISH) of metaphase chromosomes. Southern blotting analyses require the patient to be informative for polymorphic loci or rely on technically difficult gene dosage experiments. Metaphase FISH hinges on the availability of mitotic figures, and the sensitivity of interphase FISH varies among different loci. Additionally, both of these techniques require considerable amounts of patient material and are labor intensive.

Tandemly repeated dinucleotide ( $\mathrm{dC}-$ $\mathrm{dA})_{\mathrm{n}}$ and $(\mathrm{dG}-\mathrm{dT})_{\mathrm{n}}$ sequences exhibit high variability in the number of copies of the repeats in the normal human population. The alleles can be amplified by PCR, employing unique primers flanking the repeats and resolved on strandseparating denaturing polyacrylamide gels. ${ }^{(2)}$ The high degree of informativeness of these polymorphisms has been successfully utilized in the detection of genetic disorders. The haplotype analysis is facilitated by the readily distinguishable polymorphic alleles of the affected versus the unaffected siblings.
Furthermore, this technique provided the initial clues for novel genetic mechanisms in Charcot-Marie-Tooth disease (genomic duplication), and Prader-Willi and Angelman syndromes (the origin of parental disomy). ${ }^{(3,4)}$

Nonetheless, the application of the dinucleotide polymorphism analysis has been restricted to inherited anomalies and solid tumors; unaffected family members and peripheral blood specimen provide the matched control DNA in these instances. ${ }^{(5)}$ The application of this technique to hematopoietic neoplasms is hindered by technical difficulties in physical separation of normal and malignant cells. Additionally, each allele is represented by a major band, followed by a series of less intense minor bands (shadow bands) that are spaced at intervals of 2 nucleotides in an autoradiogram; ${ }^{(6)}$ overlap between a second allele and the shadow band can pose problems in the interpretations.

In this report we demonstrate detection of allele loss, by comparing the ratio between the amplified products of the two alleles in fractions enriched in normal and transformed cells. The model system of choice was the interstitially deleted chromosome $5 q(5 q-$ chromosome), which is a frequent anomaly in acute myelogenous leukemia (AML) and preleukemic myelodysplasia. A highly informative dinucleotide polymorphism in the fourth intron of the interleukin-9 (IL9) gene on 5q31 was studied in detail. ${ }^{(7)}$ The technique described here can be extended to other hematolymphoid neoplasms harboring numerical and interstitial chromosomal anomalies. 


\section{MATERIALS AND METHODS}

\section{Blood Separation and DNA Isolation}

Peripheral blood samples from patients with $5 q$-chromosome were separated on Ficoll-Hypaque gradients to yield interface mononuclear and pelletted granulocyte-enriched populations. The peripheral blood mononuclear-derived $\mathrm{T}$ cells were short-term cultured in some cases. Direct bone marrow harvests were used in cases where the material was limited. DNA isolation was as described previously. ${ }^{(8)}$ In cases where the sample was limiting, the cells $\left(1 \times 10^{5}\right)$ were lysed, treated with proteinase $\mathrm{K}$ for $10 \mathrm{~min}$ at $50^{\circ} \mathrm{C}$, and boiled for $2 \mathrm{~min}$. The cells were then centrifuged in a microcentrifuge, and a $2-\mu l$ aliquot of the supernatant was used for the amplification reaction.

\section{Cases}

Routine cytogenetic studies were done on all patients as detailed elsewhere. ${ }^{(8)}$ The data presented in Figure 4 (below) were from a Southwest Oncology Group patient originally presenting to the City of Hope National Medical Center. This patient, diagnosed in July 1990 with AML with (8:21)(q22:q22) as the sole anomaly, relapsed in April of 1991 with numerous additional cytogenetic anomalies, including a deletion $5 q(31-35) .^{(8)}$ The mononuclear population was isolated at presentation and two subsequent stages of relapse (April and July 1991).

\section{PCR}

Each reaction consisted of $\sim 50 \mathrm{ng}$ of DNA, $0.5 \mu \mathrm{M}$ each primer, $13 \mathrm{nM}^{32} \mathrm{P}$-endlabeled primer, $250 \mu \mathrm{M}$ each deoxynucleoside triphosphate, $10 \mathrm{~mm}$ Tris- $\mathrm{HCl}$ (pH 8.4), $40 \mathrm{~mm} \mathrm{NaCl}, 2.0 \mathrm{~mm} \mathrm{MgCl}_{2}, 5$ units of Taq DNA polymerase, and $0.6 \mathrm{M}$ formamide in a volume of $25 \mu 1 .{ }^{(9)}$ The end labeling of the primer was as described by Lupski et al. ${ }^{(3)}$ Two pairs of primers were tested to amplify the IL9 dinucleotide polymorphism in normal population. Primer pair $15^{\prime}$-CTAATGCAGAGATTTAGGGC-3'(dG-dT strand) and $5^{\prime}$ GTGGTGTAAAGACTGCATAG-3' $(\mathrm{dC}-\mathrm{dA}$ strand $)^{(7)}$ and primer pair II consisted of 5'-AGGCTTTCTCTAATGCAGAG-3' and 5'GGTGGTTGACCTCAAATTGG-3' ${ }^{\prime}{ }^{(10)}$ The amplifications were performed as detailed below: (1) 1 cycle at $94^{\circ} \mathrm{C}$ for 5 min; (2) 30 cycles, each at $94^{\circ} \mathrm{C}$ for 1 $\min , 55^{\circ} \mathrm{C}$ for $1 \mathrm{~min}$, and $72^{\circ} \mathrm{C}$ for $1 \mathrm{~min}$; and (3) 1 cycle at $72^{\circ} \mathrm{C}$ for $10 \mathrm{~min}$. After PCR, $25 \mu \mathrm{l}$ of stop solution [ $98 \%$ formamide, $0.05 \%$ bromophenol blue, $0.05 \%$

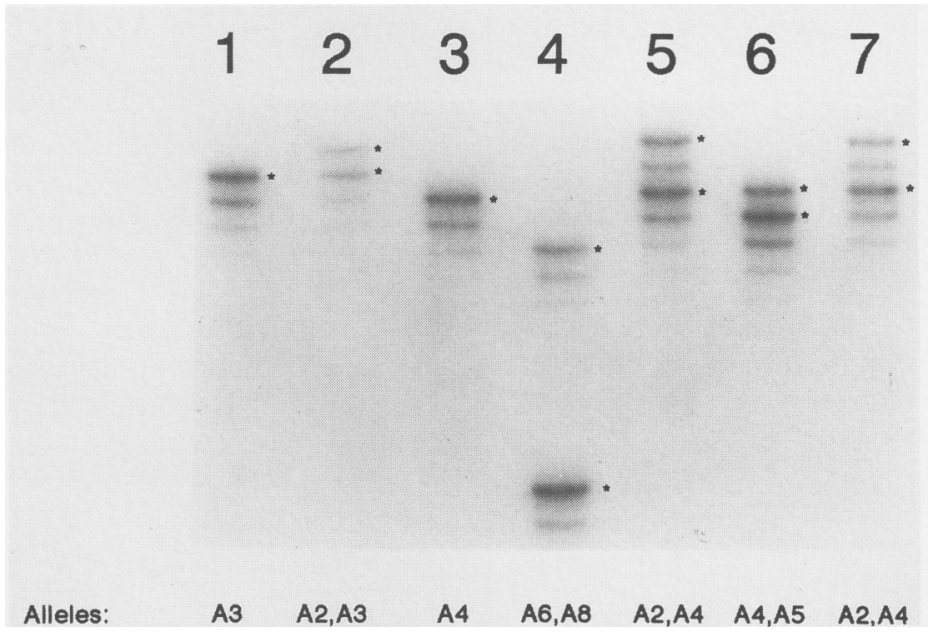

FIGURE 1 Assessment of the dinucleotide polymorphism in the IL9 gene in normal humans. Peripheral blood mononuclear DNA isolated from seven normal volunteers was amplified using end-labeled sense primer of primer pair II (as described in Materials and Methods) with formamide at $2.5 \%$ and $2.0 \mathrm{mM} \mathrm{MgCl}$. The amplification product $(2 \mu \mathrm{l})$ was resolved on a $7 \%$ denaturing polyacrylamide gel. $(*)$ Alleles. The previously reported alleles A2-A6 are seen. ${ }^{(7)}$ These would correspond to (dG-dT) $)_{n}$ of 27-19, and a novel eighth 101-bp allele, which would be the product of an allele with 10 (dG-dT) sequences. (Lanes 1,3) Individuals who are homozygous for the $\mathrm{A} 3$ and $\mathrm{A} 4$ alleles. Note that the smaller allele shows a stronger amplification than the larger allele in every informative sample, i.e., (lane 2) A3 $>\mathrm{A} 2$; (lane 4) $\mathrm{A} 8>\mathrm{A} 6$; (lane 5) $\mathrm{A} 4>\mathrm{A} 2$; (lane 6 ) A5 $>$ A4; (lane 7) A4>A2.

xylene cyanol, and $20 \mathrm{~mm}$ EDTA $(\mathrm{pH}$ 8.0)] was added to each sample. One microliter of the sample was then loaded onto an $8 \%$ polyacrylamide gel containing $7 \mathrm{~m}$ urea, $450 \mathrm{~mm}$ Tris-borate $(\mathrm{pH}$ 7.5), and 10 mM EDTA (pH 8.0). The preelectrophoresis of the gels was for $\sim 30$ min at a constant power of $50 \mathrm{~W}$ per gel in $45 \mathrm{~mm}$ Tris-borate ( $\mathrm{pH} \mathrm{7.5)}$ and $1 \mathrm{~mm}$ EDTA ( $\mathrm{pH}$ 7.0) running buffer. Loaded gels were electrophoresed for 3-4 hr. The gels were dried and exposed to $\mathrm{x}$-ray films from $2 \mathrm{hr}$ to overnight at $-70^{\circ} \mathrm{C}$, and the autoradiograms were analyzed for genotypes of the dG-dT repeat alleles.

\section{Quantitation of Amplification}

Samples were analyzed on a Molecular Dynamics PhosphorImager for the determination of the ratio of the two alleles. Selected bands were marked on the gel. Samples were cut out from the dried polyacrylamide gels and counted on a Beckman LS1800 scintillation counter (Beckman Scientific Instruments, Irvine, CA).

\section{Fluorescence-activated Cell Sorting (FACS)}

FACS for combination of $\mathrm{CD}$ antigens was performed as described previously. ${ }^{(11)}$

\section{RESULTS}

\section{Assessment of the dG-dT Polymorphism at the Fourth Intron of the 119 Gene}

Figure 1 shows the amplification pattern of seven normal human mononuclear samples. The choice of primers was critical to enhance the specificity of amplification. Use of end-labeled primer pair II was found to amplify the unique IL9 alleles with a minimum of nonspecific bands, whereas primer pair I yielded a large number of nonspecific bands.

\section{Correlation between Allele Representation and Amplification}

The sensitivity of the assay conditions described in Figure 1 was tested for their ability to detect alterations in gene dosage. Amplifications were calibrated as a function of allele representation by titrating a mixture of cells from two nor- 
mal individuals over a range of cell number. The peripheral blood mononuclear cells from two individuals who were homozygous for the alleles A3 and A4, which are 2 bp apart (Fig. 1, lanes 1,3), were mixed at $10 \%$ increments, and the DNA was isolated. Amplifications of the DNA mixtures thus obtained are depicted in Figure 2A. The intensity of A3 bands diminishes with an increase in the intensity of A4 band.

The magnitude of amplification of al- the shadow band (A3) and the specific amplification (A4). It is seen that when both the alleles are equally represented (50:50) the ratio of amplification observed is 0.65 . This value is highly reproducible in the normal population. The ratio between the upper and lower alleles is estimated to be 0.65 for other samples that are 2 bp apart [Fig. 1, lanes 2 $(\mathrm{A} 2, \mathrm{~A} 3)$ and $6(\mathrm{~A} 4, \mathrm{~A} 5)]$. As this is the smallest expected difference between alleles, the normal ratio between any in- formative sample will be $\leqslant 0.65$ for the IL9 dinucleotide polymorphism.

\section{Detection of Allele Loss in Patients with the 5q-Chromosome}

Figure 3 illustrates detection of allele loss in the peripheral blood samples of patients with myeloid disorders. A patient who revealed the two distinct alleles, in either the Ficoll buoyant or pelletted population and retained a single allele in

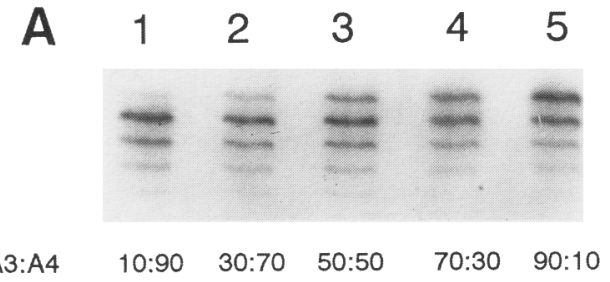

FIGURE $2(A)$ Titration of two alleles, which are 2 bp apart. Normal mononuclear cells from two individuals who were homozygous for the A3 and A4 alleles (Fig. 1, lanes 1,3) were mixed at the indicated ratio, and the DNA was isolated. Amplifications were performed as described in Materials and Methods. (B) Correlation between allele representation and amplification. The alleles were marked and the band intensity measured in a PhosphorImager. Values are represented as the ratio between intensity of allele $\mathrm{A} 3$ to $\mathrm{A} 4$. Each value represents the mean of three separate amplification reactions. $(C)$ The alleles identified in $A$ were marked, and the bands cut out from the dried strand-separating gels and counted in a liquid scintillation counter. Values are represented as the ratio between intensity of allele A3 to A4. Each value represents the mean of three separate amplification reactions.

leles A3 and A4 was quantitated in the PhosphorImager, and the ratio of amplification between $\mathrm{A} 3$ and $\mathrm{A} 4$ allele was determined over a range of varying cell numbers. Figure 2B shows that there is a direct correlation between allele representation and amplification. These results were confirmed further by cutting out the bands from a strand-separating gel and determining the amount of radioactive nucleotide incorporated into each of the bands by scintillation counting (Fig. 2C). Figure 2, B and $\mathrm{C}$ reveals that the allele ratio portrays a simple straight line mathematical representation in spite of a small overlap between
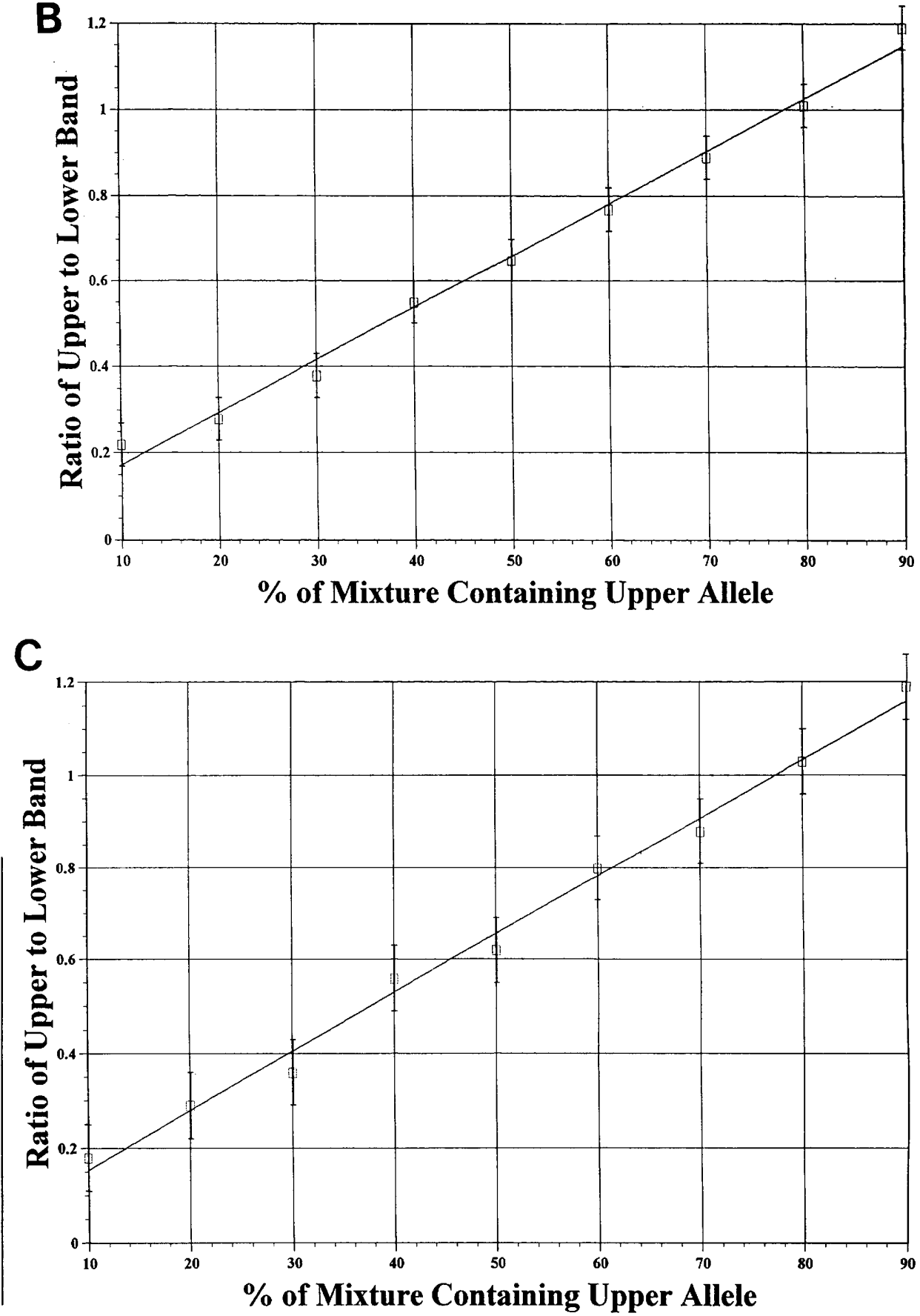


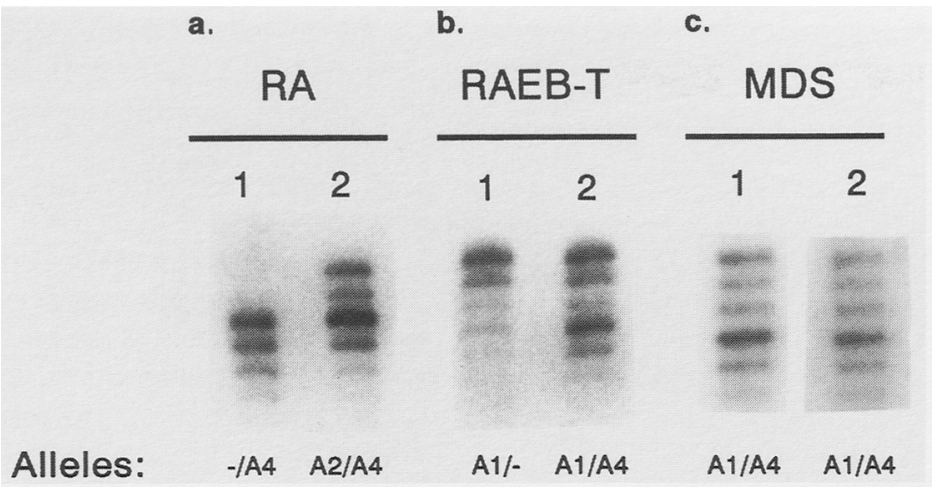

FIGURE 3 Detection of allele loss in patients with $5 q$-chromosome. Peripheral blood samples were fractionated on Ficoll-Hypaque. DNA isolated from each fraction was amplified and resolved as described in Fig. 1. (Lane 1) Ficoll pelletted population; (lane 2) Ficoll buoyant population. Please note the granulocytes of RA and RAEBT $(a$ and $b$ ), respectively patients show loss of heterozygosity. (c) A diploid MDS patient (with $28 \%$ blasts) who retains two alleles of $I L 9$ in both fractions.

the other, was considered to show loss of heterozygosity. The qualitative differences between the mononuclear and granulocytic population in representative cases are shown in Figure 3. Lane 1 of Figure $3 a$, shows that in a case of refractory anemia (RA), the peripheral blood granulocytes are derived entirely from a population that has only the A4 allele, whereas the mononuclear cells contain both A2 and A4 alleles (lane 2). Similarly, Figure $3 b$ reveals that the peripheral blood granulocytes of a patient with refractory anemia with excess blasts in transformation (RAEBT), preferentially amplify the A1 allele (lane 1) in contrast with the mononuclear cells that amplify A1 and A4 alleles (lane 2). Figure $3 c$ is a representative diploid myelodys-

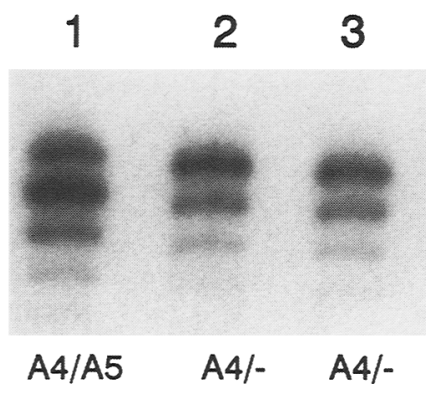

\section{Alleles: A4/A5 A4/- A4/-}

FICURE 4 Detection of $5 q$ - chromosome during the evolution of AML. (Lane 1) Mononuclear blast DNA ( $\sim 50 \mathrm{ng})$ at presentation, (lanes 2,3) Two samples of DNA ( $\sim 50 \mathrm{ng}$ ) during subsequent relapses were amplified for the dinucleotide polymorphism within the IL9 gene. The ratios between A4 and A5, as measured in a PhosphorImager, are 0.66 (lane 1); 1.32 (lane 2); 1.36 (lane 3). plastic patient with $28 \%$ blasts in the bone marrow. As expected, this patient retains the two alleles of IL9 in both of the fractions.

Figure 4 is an example of a common clinical situation in which only the mononuclear fractions of a patient were isolated at presentation and relapse. This patient presented with the cytogenetic anomaly $t(8 ; 21)$. The relapse samples had a $5 \mathrm{q}$ - chromosome in addition to $t(8 ; 21)$. As evident from lane 1 of Figure 4 , the mononuclear blast population of this patient, at presentation retained alleles A4 and A5, whereas both the relapse samples (lanes 2,3) show preferential amplification of A4 revealing a loss of the $A 5$ allele. The ratio of amplification between the A4 and A5 alleles at presentation was 0.66 , suggesting that the original leukemic cells were not a mixture of cells with and without the $5 q$ - chromosome. The ratio between the alleles at both stages of relapse was $>1.3$; extrapolating this ratio to the data shown in Figures $2 \mathrm{~B}$ and $\mathrm{C}$, we can conclude that the mononuclear leukemic blast population of $<90 \%$ from this patient carries the $5 q-$ anomaly.

\section{IL9 Gene Resides Within the Region of Loss in 5q-Chromosome}

The analyses were extended to a large number of patients with $5 q-$ chromosome. The ratios between the alleles were determined as detailed in Figure, 2B and $\mathrm{C}$ for the Ficoll buoyant and pelletted fractions. The presence of two alleles in the mononuclear lymphoid cells or short-term cultured $\mathrm{T}$ cells rendered them informative for the IL9 polymorphism.

Table 1 shows the data obtained from seven informative cases. The ratio between the amplifications of the upper to lower alleles in the Ficoll buoyant and pelletted cells of these patients was determined by the PhosphorImager. The allele loss is readily detectable as an altered ratio in the appropriate lineage of peripheral blood. Of these, cases 1 and 2 correspond with the data depicted in Figure $3 a$ and $b$, respectively. Data for patient 3 was obtained from similar experiments. In contrast with patients 1-3, the Ficoll buoyant and pelletted fractions are both derived from the $5 q-$ clone in the case of AML (patient 4). Short-term cultured T lymphocytes provided evidence for diploid status of normal cells.

As expected, the ratio has a higher value in cases where the deleted allele is smaller (patients 2-6). Loss of the larger allele would result in a smaller ratio in the affected population as evident from cases 1 and 7 .

A number of conclusions can be drawn from the data presented in Table 1. (1) In cases of myelodysplastic syndromes (MDS, i.e., RA and RAEBT), the Ficoll pelletted samples show allele loss, whereas the buoyant samples, which include lymphoid cells, show retention of two alleles (patients 1-3). (2) In contrast, the AML cases are heterogenous. Patient 4 shows allele loss in both the Ficoll buoyant and pelletted fractions, whereas the short-term cultured $\mathrm{T}$ lymphocytes reveal the heterozygous nature. (3) The pelletted samples of patients 5 and 6 show the presence of two alleles, and the mononuclear fraction is enriched in blasts that have lost an allele. (4) Samples from patient 7 , from whom only the mononuclear population was obtained, clearly demonstrate allele loss during the progression of the disease. (5) All of the seven informative cases show allele loss for IL9.

\section{Clonality Analysis of Cells Exhibiting Rare Immunophenotypes (RIPs)}

Expression of specific cell-surface markers (CD antigens) at distinct stages of differentiation is a hallmark of normal hematopoiesis. ${ }^{(11)}$ In contrast, the leukemic bone marrow presents cells with a unique subset of $C D$ antigens that do not 
TABLE 1 Loss of Heterozygosity for IL9 in 5q- Patients

\begin{tabular}{|c|c|c|c|c|}
\hline Patient no. & Diagnosis & Fraction $^{a}$ & Ratio & Alleles $^{\mathrm{b}}$ \\
\hline 1 & RA & B & $0.62 \pm 0.02$ & $\mathrm{~A} 2, \mathrm{~A} 4$ \\
\hline 1 & RA & $\mathrm{P}$ & $0.18 \pm 0.04$ &,$- \mathrm{A} 4$ \\
\hline 2 & RAEB-T & B & $1.4 \pm 0.2$ & $\mathrm{~A} 1, \mathrm{~A} 4$ \\
\hline 2 & RAEB-T & $\mathbf{P}$ & $3.1 \pm 0.6$ & $\mathrm{~A} 1,-$ \\
\hline 3 & MDS & B & $0.72 \pm 0.03$ & $\mathrm{~A} 1, \mathrm{~A} 2$ \\
\hline 3 & MDS & $\mathrm{P}$ & $0.93 \pm 0.06$ & $\mathrm{~A} 1,-$ \\
\hline 4 & AML & B & $0.87 \pm 0.06$ & $\mathrm{~A} 2,-$ \\
\hline 4 & AML & $\mathrm{P}$ & $0.80 \pm 0.05$ & $\mathrm{~A} 2,-$ \\
\hline 4 & AML & $\mathrm{T}$ & 0.65 & $\mathrm{~A} 2, \mathrm{~A} 3$ \\
\hline 5 & AML & B & $1.08 \pm 0.04$ & $\mathrm{~A} 3,-$ \\
\hline 5 & AML & $\mathrm{P}$ & $0.64 \pm 0.02$ & $\mathrm{~A} 3, \mathrm{~A} 4$ \\
\hline 5 & AML & $\mathrm{T}$ & $0.64 \pm 0.01$ & $\mathrm{~A} 3, \mathrm{~A} 4$ \\
\hline 6 & AML & B & $1.07 \pm 0.04$ & $\mathrm{~A} 3,-$ \\
\hline 6 & AML & $\mathbf{P}$ & $0.66 \pm 0.04$ & $\mathrm{~A} 3, \mathrm{~A} 4$ \\
\hline 7 & AML & BM Mn presentation & $0.66 \pm 0.01$ & A4, A5 \\
\hline 7 & AML & BM Mn relapse I & $1.32 \pm 0.04$ & $\mathrm{~A} 4,-$ \\
\hline 7 & AML & BM Mn relapse II & 1.36 & $\mathrm{~A} 4,-$ \\
\hline
\end{tabular}

${ }^{\mathrm{a}}$ (B) Ficoll buoyant; (P) Ficoll pelleted; (T) T cells; (BM) bone marrow; (Mn) mononuclear (cells). b(A1) 129 bp; (A2) 127 bp; (A3) 125 bp; (A4) 123 bp; (A5) 121 bp; (A6) 119 bp; (A7) 117 bp.

follow the normal pattern of expression. RIPs are present in $95 \%$ of leukemias. To identify the origin of RIPs, cells from a $5 q-$ AML patient (Table 1, patient 5) were separated by FACS and analyzed (Fig. 5; Table 2). T cells expressing $\mathrm{CD}^{+}$ served as control, and cells coexpressing $\mathrm{CD} 33^{+}$and $\mathrm{CD}^{+}$(RIPs) were analyzed for the presence of the $5 \mathrm{q}-$ chromosome. As seen in Table 2, the cells exhibiting the RIP have a higher ratio indicating that this population has lost the smaller allele. Therefore, the RIP cells are derived from the $5 q$ - clone.

Interestingly, the $\mathrm{CD}^{+}$cells were significantly different from the expected ratio of 0.65 and yielded a $0.8 \pm 0.1$ ratio of upper to lower allele. Upon examination of the $\mathrm{T}$ cells induced to proliferate in vitro with phytohemagglutinin and IL2, it is evident that the ratio is the expected 0.65 (Table 1, patient 5). This suggests that a subpopulation of cells expressing the CD3 marker were derived from the $5 q-$ clone and were not inducible by T-cell mitogens.

\section{DISCUSSION}

Dinucleotide repeat polymorphisms occur approximately once in $30-40 \mathrm{kbp}$ of the human genome. Therefore, the entire genome can be represented by a large number of $\mathrm{dC}-\mathrm{dA}$ or $\mathrm{dG}-\mathrm{dT}$ repeat
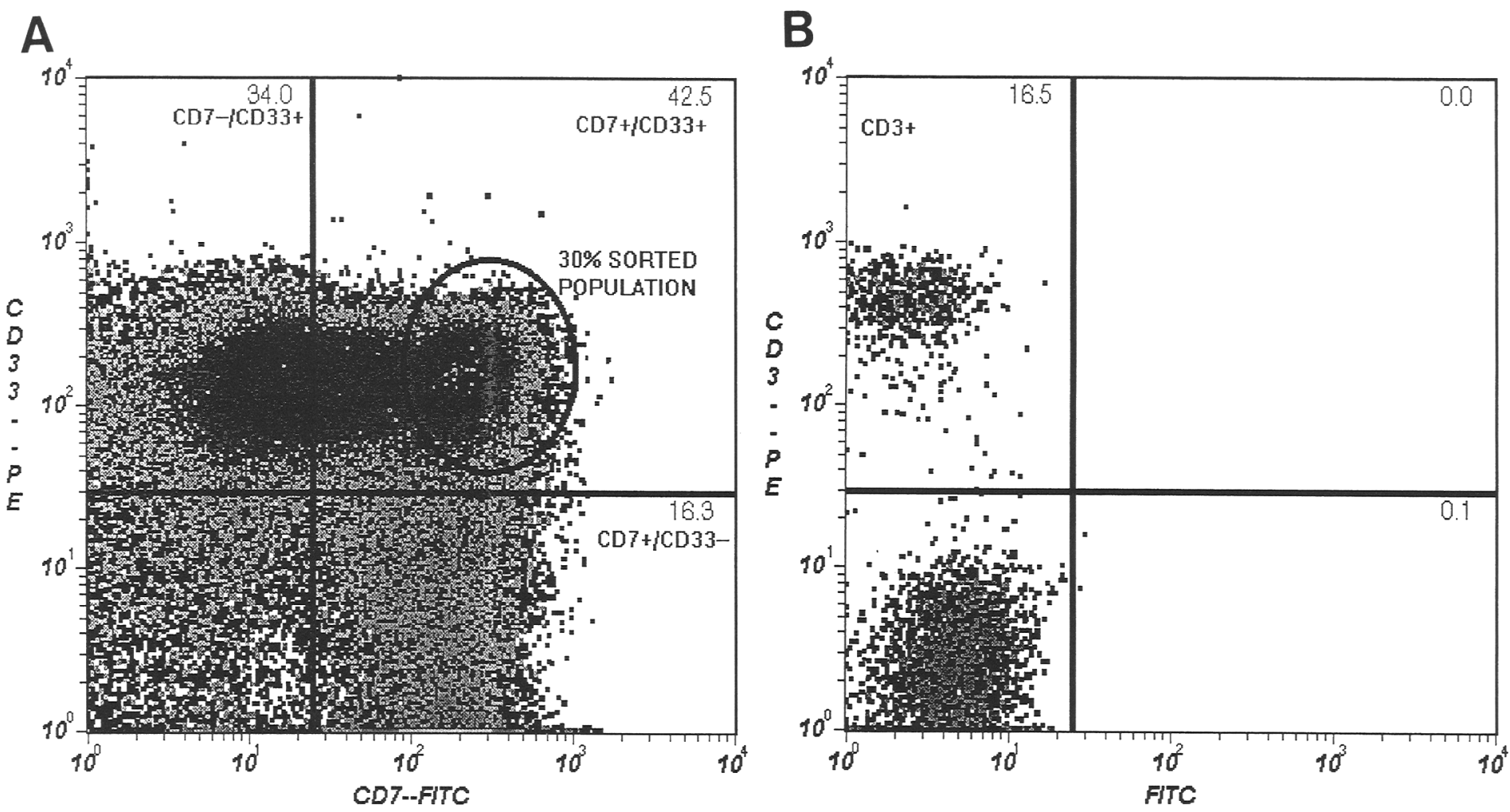

FIGURE 5 Flow cytometry sort windows for subpopulations of cryopreserved leukemic cells, sample 5 of Table 1 . $(A)$ Cells were stained with anti-CD7 (FITC conjugate) and anti-CD33 (phycoerythrin conjugate). Coexpressing cells were sorted using the window as shown. On reanalysis, sorted cells were $98 \% \mathrm{CD}^{+} / \mathrm{CD}^{2} 3^{+}$. This phenotype is considered rare or abnormal in hematopoetic cells and thus is a putative marker for leukemia. (B) Cells were stained with anti-CD3 antibody (phycoerythrin conjugate). Of the gated cells, $15.7 \%$ expressed CD3 and were sorted using

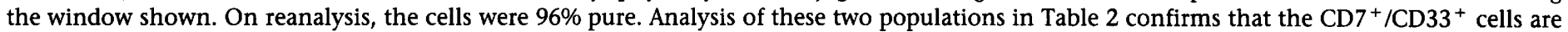
derived from the $5 q-$ clone. 
TABLE 2 Rare Immunophenotype Analysis

\begin{tabular}{llclr}
\hline Patient & Fraction & Immunophenotype & $\begin{array}{l}\text { PhosphorImager } \\
\text { ratio }\end{array}$ & Alleles \\
\hline 5 & T cells & $\mathrm{CD}^{+}$ & $0.8 \pm 0.1$ & $\mathrm{~A} 3, \mathrm{A4}$ \\
5 & RIP & ${\mathrm{CD} 33^{+} / \mathrm{CD}^{+}}^{+}$ & $1.04 \pm 0.05$ & $\mathrm{~A} 3,-$ \\
\hline
\end{tabular}

Amplifications were done with aliquots of 25 and 50 cells, respectively.

sequences that are frequently heterozygous in the normal human population. ${ }^{(2)}$ The high degree of informativeness can be exploited in the detection of recurrent numerical and interstitial anomalies seen in hematolymphoid neoplasms.

The dinucleotide repeat analysis has been employed in detecting allele loss in solid tumors, as the hematopoietic samples or the normal tissues from these patients serve as control for the diploid state. ${ }^{(5)}$ The major impediment associated with detecting allele loss in hematolymphoid specimens is the availability of relatively enriched normal and malignant cells. Generation of shadow bands during the PCR reaction further compounds this problem.

A recent report by Hauge and Litt has illustrated that the shadow bands are entirely caused by a variation in the length of the dinucleotide repeats caused by slipped strand mispairing during the amplification reaction. ${ }^{(6)}$ This proposal is supported by our findings that (1) the shadow bands only appear below and not above the major allelic bands; (2) smaller alleles seem to have a higher ratio of major band to shadow band; and (3) the addition of formamide, known to dissociate DNA secondary structures in GC-rich regions, reduces this problem.

Other possible sources of errors in interpretation are (1) the unequivalent amplification of alleles within the same sample; and (2) the unequivalent amplification of the same sample during different attempts. These issues are alleviated by comparing the allele ratios among lineages during the same reaction. Regardless of the extent of sample amplification, the ratio of amplification between a pair of normal alleles remains consistent and reproducible.

Results presented in Figures 1 and 2 stress the need for optimization of amplification conditions for a given locus. Amplification of the IL9 locus has been utilized previously to demonstrate that the myeloid and not lymphoid cells are derived from the abnormal clone in AML and MDS patients with 5q- chromosome; using monocytes $\left(\mathrm{CD} 14^{+}\right.$, $\left.\mathrm{CD}_{4} 5^{+}\right)$and lymphoid cells $\left(\mathrm{CD} 20^{+}\right)$ separated by FACS, Kroepf et al. ${ }^{(12)}$ showed restriction of allele loss in the myeloid lineage in four patients. Using primer pair I (as described in Materials and Methods), they identified a cluster of hard-to-interpret bands when the amplification products were resolved on a denaturing gel. ${ }^{(12)}$ Consequently, the PCR products were analyzed on a nondenaturing gel as altered single-strand confirmation (SSCP) polymorphisms. The reported sensitivity of SSCP assays under optimal conditions can range from $97 \%$ to $70 \%$, depending on the amplified sequences. ${ }^{(13)}$ Therefore, an informative polymorphism or allele loss may go undetected.

Data in Figure 1 demonstrate that the use of primer pair II and the inclusion of formamide minimized amplification anomalies. Hence, the samples could be resolved on denaturing gels in contrast with the nondenaturing gels, which are harder to cast. These results stress the need for optimization of PCR conditions for a given locus. Figure 2, B and C, demonstrate further that the amplification reactions are a direct correlate of allele representation even when alleles are separated by 2 bp. Despite the higher levels of amplification of the smaller allele and the presence of an overlapping shadow band, we observe that the alleles are amplified as a function of their dosage. These amplification patterns are reproducible within the limits of experimental errors and allow us to apply this technique for qualitative detection of the $5 q$ - chromosome. We have observed similar amplification patterns for several other ( $\mathrm{dC}-\mathrm{dA})$ dinucleotide loci (J. Fairman and L. Nagarajan, unpubl.).

The technique described in this report is not quantitative. Development of a panel of normal population with all of the probable allele combinations may facilitate further refinement of the tech- nique and permit quantitation. As evident from the data presented in Table 1, the allele loss is always seen in the Ficoll buoyant mononuclear blast fractions in cases of AML; this may or may not be accompanied by loss of heterozygosity in the sedimented fractions. Nonetheless, the present analysis allows the determination of whether a patient is $5 q-$ or -5 in a relatively short period of time (24-36 hr), using 1-2 $\mathrm{ml}$ of peripheral blood or bone marrow.

As shown in Table 1 (patient 4), the granulocytic and blast populations may be derived from the $5 q$ - clone in AML. In these cases, the amplification using DNA isolated from $T$ cells (Table 1), skin tissue, or hair root would provide a true diploid comparison from the patient. Also, a basal mucosal scrape could be used, provided the patient was administered a mouthwash first to eliminate the dead neutrophils on the tongue. In cases of leukemia, peripheral blood samples isolated at stages of presentation, remission, and relapse can be compared. The dinucleotide analysis, if performed on FACS populations or colonies grown from sorted cells (during remission), can be used to detect minimal residual disease.

Besides the clinical and diagnostic applicability, several inferences may be drawn: (1) The peripheral blood granulocytes of patients with $5 q-$ syndrome (transfusion-dependent refractory anemia) are derived entirely from the $5 q-$ clone (Fig. 3a, lanes 1,2). (2) The 5q31 locus spanning $I L 9$ is deleted during the evolution of the disease in a case of AML [M2 with $t(8 ; 21)]$ (Fig. 4, lanes 1-3). (3) The IL9 gene lies within the critical region of loss in a vast majority of $5 q^{-}$ cases studied; these findings are analogous to an earlier study employing FISH, ${ }^{(14)}$ showing loss of the IL9 locus in five out six $5 q-$ cases.(4) The rare immunophenotypes seen in AML are derived from the transformed population.

(5) Cytogenetically, diploid MDS and AML cases show no loss of the IL9 locus (data not shown).

Characterization of additional dinucleotide polymorphisms from the $5 q 31$ region could lead to delineation of the smallest region of loss; an added advantage is the ability to survey a large number of patients with minimal material. Finally, this technique could be extended to the detection of any deletion, amplification, or interstitial anomaly, 
which would result in an altered allele ratio. Our results warrant the need for rigorous optimization of the amplification conditions prior to use in diagnosis or research.

\section{ACKNOWLEDGMENTS}

We thank Leslie Calvert and Joy Hamer for coordinating patient material; Drs. Wei Zhang and Elie Hanania for helpful discussions; Drs. Arlinghaus and Guo for the use of the PhosphorImager; Senan Baron for assistance with the FACS; Jiri Zavadil for critical reading of the manuscript. We also thank Rosemarie Lauzon and Joyce Palmer for assisting in the preparation of the manuscript. This work was supported by the National Institutes of Health (PO1 CA55164 to L.N. and A.D., CA32102 to C.L.W.), the American Cancer Society (DHP-44 to L.N.), and grants from the Sid Richardson Foundation, the Gillson-Longenbaugh Foundation, the Anderson Chair for Cancer Treatment and Research, and the Kleberg Foundation (to A.D).

\section{REFERENCES}

1. Heim, S. and F. Mitelman. 1992. Cytogenetic analysis in the diagnosis of acute leukemia. Cancer (Suppl.) 70: 1701-1709.

2. Weber, J.L. 1990. Informativeness of human $(\mathrm{dC}-\mathrm{dA})_{\mathrm{n}}(\mathrm{dG}-\mathrm{dT})_{\mathrm{n}}$ polymorphisms. Genomics 7: 524-530.

3. Lupski, J.R., R. Montes de Oca-Luna, S. Slaugenhaupt, L. Pentao, V. Guzzetta, B.J. Trask, O. Saucedeo-Cardenas, D.F. Barker, J.M. Killian, C.A. Garcia, A. Chakravarti, and P.I. Patel. 1991. DNA duplication associated with Charrot-Marie-Tooth disease type 1A. Cell 66: 219-232.

4. Mutirangura, A., F. Greenberg, M.G. Butler, S. Malcolm, R.B. Nicholls, A. Chakravarti, and D.H. Ledbetter. 1993. Multiplex PCR of three dinucleotide repeats in the Prader-Willi/Angelman critical region (15q11-q13): Molecular diagnosis and mechanism of uniparental disomy. Hum. Mol. Genet. 2: 143-151.

5. Daly, M.C., R.-H. Xiang, D. Buchhagen, C.H. Hensel, D.K. Garcia, A.M. Killary, J.D. Minna, and S.L. Naylor. 1993. A homozygous deletion on chromosome 3 in a small cell lung cancer cell line correlates with a region of tumor suppressor activity. Oncogene 8: 1721-1729.

6. Hauge, X.Y. and M. Litt. 1993. A study of the origin of "shadow bands" seen when typing dinucleotide repeat polymorphisms by the PCR. Hum. Mol. Genet. 2: 411-415.

7. Polymeropoulos, M.H., H. Xiao, D.S.
Rath, and C.R. Merri. 1991. Dinucleotide repeat polymorphism at the human interleukin 9 gene. Nucleic Acids Res. 19: 688.

8. Nagarajan, L., J. Zavadil, D. Claxton, X. Lu, J. Fairman, J. Warrington, J. Wasmuth, A.C. Chinault, C.E. Sever, M.C. Slovak, C.L. Willman, and A.B. Deisseroth. 1994. Consistent loss of the D5S89 locus mapping telomeric to the interleukin gene cluster and centromeric to egr 1 in patients with $5 q$ - chromosome. Blood 83: 199-208.

9. Sarkar, G., S. Kapelner, and S.S. Sommer. 1991. Formamide can dramatically improve the specificity of PCR. Nucleic Acids Res. 18: 7465.

10. ATCC/NIH repository catalogue of human and mouse DNA probes and libraries. 1993. p. 145. Seventh edition.

11. Reading, C.L., E.H. Estey, Y.O. Huh, D.C. Claxton, G. Sanchez, L.W.M.M. Terstappen, M.C. O'Brien, S. Baron, and A.B. Deisseroth. 1993. Expression of unusual immunophenotype combinations in acute myelogenous leukemia. Blood 81: 30833090.

12. Kroef, M.J.P.L., W.E. Fibbe, R. Mout, R.P.M Jansen, H.L. Haak, J.E. Wessels, H. Van Kamp, R. Willemze, and J.E. Landegent. 1993. Myeloid but not lymphoid cells carry the $5 q$ deletion: Polymerase chain reaction analysis of loss of heterozygosity using mini-repeat sequences on highly purified cell fractions. Blood 81: $1849-1854$.

13. Sheffield, V.C., J.S. Beck, A.E. Kwitek, D.W. Sandstrom, and E.M. Stone. 1993. The sensitivity of single-strand conformation polymorphism analysis for the detection of single base substitutions. Genomics 16: 325-332.

14. Le Beau, M.M., R. Espinosa III, W.L. Neumann, W. Stock, D. Roulston, R.A. Larson, M. Keinanen, and C. Westbrook. 1993. Cytogenetic and molecular delineation of the smallest commonly deleted region of chromosome 5 in malignant myeloid diseases. Proc. Natl. Acad. Sci. 90: 5484-5488.

Received April 11, 1994; accepted in revised form June 20, 1994. 


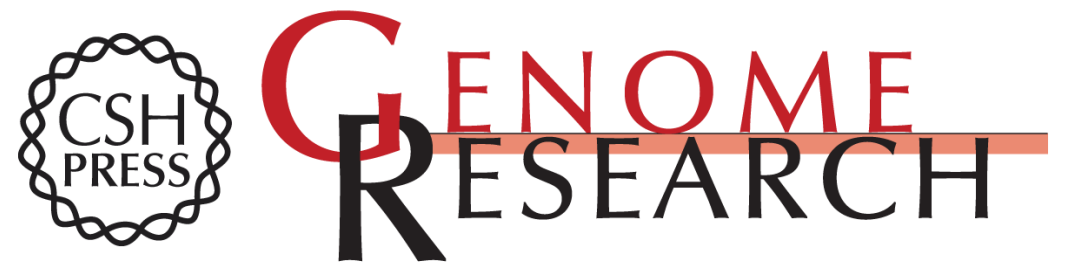

\title{
Development of a sensitive PCR to detect allele loss in a model hematopoietic neoplasm.
}

\author{
J Fairman, D Claxton, C L Williman, et al.
}

Genome Res. 1994 4: 6-12

References This article cites 13 articles, 4 of which can be accessed free at:

http://genome.cshlp.org/content/4/1/6.full.html\#ref-list-1

License

Email Alerting Receive free email alerts when new articles cite this article - sign up in the box at the Service top right corner of the article or click here.

\section{Affordable, Accurate Sequencing.}

\section{gencove}

To subscribe to Genome Research go to: https://genome.cshlp.org/subscriptions 